\title{
Incidência e etiologia de uveítes em Curitiba
}

\author{
Incidence and etiology of uveitis in Curitiba
}

Marcelo Luis Gehlen ${ }^{(1)}$

Vanessa Maria Dabul (2)

Sílvio Seiji Obara ${ }^{(2)}$

Sara Patrícia Grebos ${ }^{(2)}$

Carlos Augusto Moreira ${ }^{(1)}$

\begin{tabular}{|l|}
\hline \multicolumn{1}{|c|}{ RESUMO } \\
\hline Objetivo: Determinar a incidência e a etiologia dos casos de uveítes \\
em Curitiba-PR. \\
Métodos: Foram estudados 68 casos de uveítes em Curitiba, PR, \\
atendidos no ambulatório de oftalmologia no período de janeiro a \\
abril de 1998 procurando estabelecer o diagnóstico a partir de ampla \\
investigação clínica e laboratorial. \\
Resultados: Em nosso estudo, constatamos que a uveíte posterior \\
foi a mais encontrada (49\%), seguindo-se a panuveíte (29\%) e, com \\
menor freqüência, a uveíte anterior (22\%). A etiologia mais freqüen- \\
te para as uveítes posteriores foi a toxoplasmose, responsável por \\
88\% dos casos. Entre as panuveítes, novamente a toxoplasmose \\
prevaleceu, com 85\% e, dentro das uveítes anteriores, a principal \\
causa foi a espondilite anquilosante com $20 \%$. \\
Conclusão: Em Curitiba, há um predomínio de uveítes posteriores \\
e panuveítes, sendo a causa mais comum a toxoplasmose. No entanto, \\
enfatiza-se que existem outras causas importantes de uveítes que \\
devem ser lembradas pelo oftalmologista na investigação clínica.
\end{tabular}

Palavras-chave: Uveíte; Toxoplasmose; Etiologia.

\section{INTRODUÇ̃̃O}

A uveíte pode ser manifestação de doenças infecciosas, reumáticas ou doenças de etiologia desconhecida. As uveítes podem ocorrer na ausência de qualquer enfermidade detectável ${ }^{1}$.

Ressalta-se também a importância epidemiológica no reconhecimento da etiologia da uveíte que varia muito com a região geográfica, sexo, etnia, idade, aspectos sociais e fatores imunológicos ${ }^{5}$.

Atualmente classificamos as uveítes segundo sua localização anatômica em anteriores, intermediárias, posteriores e panuveítes. Ainda pelo aspecto biomicroscópico pode-se diferenciar lesões granulomatosas das não granulomatosas ${ }^{3}$.

Em uma população de 100.000 pessoas, no período de um ano, aproximadamente 15 novos indivíduos apresentarão uveíte ${ }^{7}$. Nos Estados Unidos acredita-se ainda que a uveíte represente cerca de $10 \%$ de todos os casos de cegueira legal ${ }^{7}$.

A toxoplasmose tem sido indicada como a uveíte mais freqüente no sul do Brasil ${ }^{1}$ e tem ocupado lugar de destaque nas alterações maculares inflamatórias.

A prevalência estimada de lesões oculares por toxoplasmose em São Paulo é estimada ao redor de 8,5 a $9 \%{ }^{5}$.

A importância deste trabalho se deve à ausência de estudo semelhante 


\section{ANÚNCIO}


no Paraná. Curitiba e região metropolitana têm, aproximadamente, 2.400.000 habitantes e considerando a prevalência de uveítes em outras populações, Curitiba deverá ter cerca de 360 novos casos de uveítes em cada ano.

O objetivo deste estudo é determinar a incidência e etiologia das uveítes na cidade de Curitiba.

\section{PACIENTES E MÉTODO}

Foi realizado um estudo prospectivo sobre os 68 casos de uveítes diagnosticados no ambulatório de oftalmologia do Hospital Universitário Evangélico de Curitiba no período de 05 de janeiro a 15 de abril de 1998. Após exame oftalmológico completo a fim de identificar o sítio anatômico da uveíte (anterior, posterior ou panuveíte), os pacientes eram submetidos ao protocolo do trabalho, onde eram pesquisados os seguintes dados:

Para uveíte anterior, constavam no protocolo as seguintes hipóteses etiológicas: SIDA, espondilite anquilosante, síndrome de Reiter, síndrome de Behçet, artrite reumatóide juvenil, herpes simples, herpes zoster, sarcoidose, tuberculose, hanseníase, trauma, iridociclite heterocrômica de Fuchs e idiopática.

Nos protocolos de uveíte posterior, constavam hipóteses etiológicas para toxoplasmose, SIDA, sífilis, sarcoidose, aspergilose, candidíase, criptococose, histoplasmose, nocardiose, cisticercose, oncocercose, toxocaríase, citomegalovírus, síndrome de Vogt-Koyanagi-Harada, doença de Lyme, poliarterite nodosa, policondrite relapsa, LES, granulomatose de Wegener, doença inflamatória intestinal, neoplasia (leucemia, linfoma, melanoma), tuberculose, hanseníase, brucelose, rubéola, necrose aguda da retina, coroidopatia do nascimento, coroidite geográfica, coroidite serpiginosa e doença de Eales.

Constavam no protocolo da panuveíte as hipóteses etiológicas de SIDA, sífilis, toxoplasmose, brucelose, sarcoidose, hanseníase, coxsackie, Epstein-Barr vírus, herpes simples, herpes zoster, rubéola, policondrite relapsa, LES, síndrome de Behçet, granulomatose de Wegener, doença inflamatória intestinal, síndrome de Vogt-Koyanagi-Harada e oftalmia simpática.

O diagnóstico era estabelecido, então, por anamnese, exame oftalmológico e exame físico completos e para cada suspeita clínica, foram solicitados exames complementares, como sorologia para toxoplasmose, para HIV, VDRL, CMV, BAAR, sorologia para rubéola, raio $\mathrm{X}$ de sacroilíacas, FAN, fator reumatóide, VHS, proteína $\mathrm{C}$ reativa e mucoproteínas.

\section{RESULTADOS}

Observou-se no presente estudo a maior freqüência de uveíte posterior (49\%), seguido de $29 \%$ de casos de panuveíte e $22 \%$ de uveíte anterior (Fig. 1).

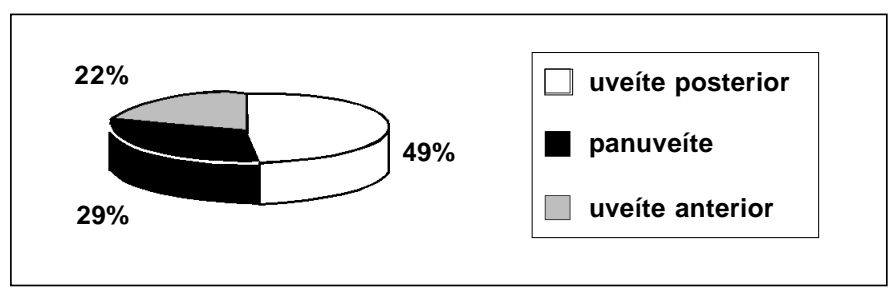

Fig. 1 - Freqüência das uveítes conforme local anatômico.

Ao analisar os resultados obtidos dos protocolos de uveíte posterior, observou-se que, esta, é causada por toxoplasmose em $88 \%$ dos casos e tendo como outras causas a toxocaríase $(3,03 \%)$, tuberculose $(3,03 \%)$, citomegalovírus $(3,03 \%)$ e de causa indeterminada $(3,03 \%)$.

A amostra de panuveíte encontrada teve como causa, em $85 \%$ dos casos, a toxoplasmose, 5\% de citomegalovírus, 5\% de síndrome de Vogt-Koyanagi-Harada e 5\% de herpes zoster.

Dentre as uveítes causadas por toxoplasmose 64\% dos casos foram representados por uveíte posterior e $36 \%$ por panuveíte. Não houve nenhum caso de uveíte anterior devido à toxoplasmose (Fig. 2).

Menos freqüente $(22 \%)$, a uveíte anterior apresentou as mais variadas causas, dentre elas destaca-se a espondilite anquilosante $(20 \%)$, doença de Fuchs (13,3\%), herpes simples $(13,3 \%)$, herpes zoster $(6,66 \%)$, doenca de Behçet $(6,66 \%)$, trauma $(6,66 \%)$ e com predomínio de causa idiopática $(33,5 \%)$ (Fig. 3).

Não houve nenhum caso de uveíte intermediária isolada na amostra estudada.

Não houve nenhum caso de paciente HIV positivo.

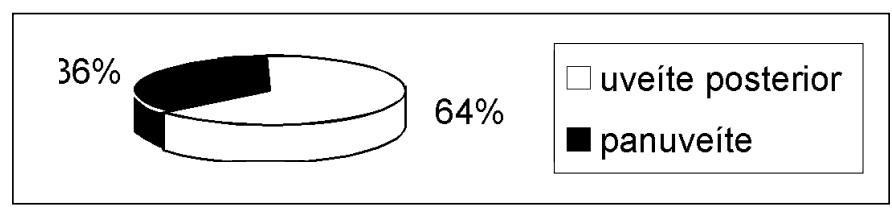

Fig. 2 - Freqüência das uveítes por toxoplasmose.

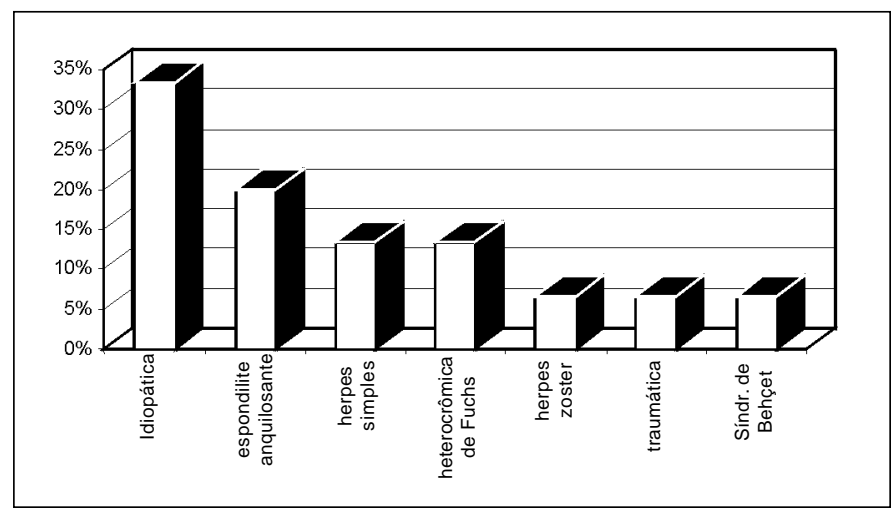

Fig. 3 - Freqüência das uveítes anteriores conforme etiologia. 


\section{ANÚNCIO}




\section{DISCUSSÃO}

A característica etiológica das uveítes difere conforme a região geográfica do planeta. Nos Estados Unidos, há maior freqüência de uveíte anterior $(51,6 \%)$, seguido da uveíte posterior $(19,4 \%)$, panuveíte $(16 \%)$, intermediária $(13 \%)^{9}$. Neste estudo, observou-se uma alta incidência de uveíte posterior (49\%) devido à grande quantidade de pacientes com toxoplasmose. Segundo a literatura estudada, cerca de $17 \%$ das panuveítes são idiopáticas ${ }^{4}$. A panuveíte esteve presente em $29 \%$ dos casos, sendo que a maioria absoluta foi representada pela toxoplasmose (17 dos 20 pacientes). Nenhum caso de panuveíte idiopática foi relatado neste trabalho.

A uveíte anterior representou $22 \%$ dos pacientes sendo que destes, 33,5\% eram de origem idiopática corroborando com os dados da literatura ${ }^{4}$.

$\mathrm{Na}$ Europa, onde a uveíte anterior é mais freqüente, a espondilite anquilosante corresponde à maioria dos casos diagnosticados $6,8,10$.

Similarmente, o presente estudo demonstrou que a espondilite anquilosante consiste na patologia diagnosticada mais comum entre as uveítes $(20 \%)$.

A toxoplasmose apresentou-se como a principal etiologia dentro das uveítes posteriores na Índia ${ }^{2}$.

Apesar da pequena amostra, este trabalho registrou uma porcentagem elevada de casos de toxoplasmose como causa principal de uveíte posterior e panuveíte. Estes dados são semelhantes aos obtidos em outras regiões brasileiras ${ }^{1}$.

Portanto, conclui-se que, em Curitiba, existe um grande predomínio de uveíte posterior tendo como causa mais freqüente a toxoplasmose $(88 \%)$. Também nos casos de panuveíte a toxoplasmose foi a causa mais comum (85\%). No entanto, deve-se enfatizar que a realização de exames clínicos e laboratoriais são imprescindíveis para o diagnóstico das demais causas de uveítes, embora menos freqüentes.

\section{SUMMARY}

Purpose: To study the incidence and etiology of uveitis in Curitiba, PR, Brazil.
Methods: Sixty-eight cases of uveitis were studied in Curitiba, PR between January and April, 1998. Clinical and laboratorial research was performed in order to establish the diagnosis.

Results: In this study, we found that posterior uveitis was the most frequent (49\%), followed by panuveitis (29\%), and, less frequently, anterior uveitis (22\%). The major etiology of posterior uveitis was toxoplasmosis, responsible for $88 \%$ of the cases; among panuveitis, toxoplasmosis also predomi-nated, representing $85 \%$ and, the main cause of anterior uveitis was ankylosing spondilytis with $20 \%$.

Conclusions: In Curitiba, posterior uveitis and panuveitis predominate, and the most frequent etiology is toxoplasmosis. However, its important to emphasize that there are other important causes of uveitis which should be remembered by the ophthalmologist during the clinical investigation.

Keywords: Uveitis; Toxoplasmosis; Etiology

\section{REFERÊNCIAS BIBLIOGRÁFICAS}

1. Abreu MT, Hirata PS, Belfort Jr. R, Domingues S. Uveítes em São Paulo: estudo epidemiológico, clínico e terapêutico. Arq Bras Oftal 1980;43:10-6.

2. Biswas J, Narain S, Das D, Ganesh SK. Pattern of uveitis in a referral uveitis clinic in India. Int Ophthalmol 1996;20:(4):223-8.

3. Martenet AC, Bischoff PM, Grobi PJ, Fierz W. Immune complexes and uveitis. In: Silverstein AM, O'Connor GR eds. Immunology and immunopathology of the eye. New York, Masson USA, 1979;55-7.

4. Merril PT, Kim J, Cox TA, Betor CC, McCallum RM, Jaffe GJ. Uveitis in the southeastern United States. Curr Eye Res 1997;16:(9):865-74.

5. Muller MEW. Incidência de toxoplasmose em bulbos oculares do Banco de Olhos de SP. Tese de Mestrado apresentada à Escola Paulista de Medicina, 1987.

6. Päivönsalo Hietanen T, Tuominen J, Vaahtoranta Lehtonen H, Saari KM. Incidence and prevalence of different uveitis entities in Finland. Acta Ophthalmol Scand 1997;75:(1):76-81.

7. Pavan-Langston D. Manual of Ocular Diagnosis and Therapy, $4^{\mathrm{a}}$ ed. 1996;181-2.

8. Pivetti Pezzi P, Accorinti M, La Cava M, Colabelli Gisoldi RA, Abdulaziz M. Endogenous uveitis: analysis of 1,417 cases. Ophthalmologica 1996;210:(4):234-8.

9. Rodriguez A, Calonge M, Pedroza Seres M, Akova YA, Messmer EM, Damico DJ, Foster CS. Referral patterns in a tertiary eye care center. Arch Ophthalmol 1996;114:15,593-9.

10. Tran VT, Auer C, Guex-Crosier Y, Pittet N, Herbort CP. Epidemiological characteristics of uveitis in Switzerland. Int Ophthalmol 1994;18:(5):293-8.

\section{Novidades na Internet!:!}

Agora no site CBO você tem disponível todas as informações na íntegraa dos

Arquivos Brasileiros de Oitalmologia

http://www.cho.com.br/abo 